\title{
OAB E AS PRERROGATIVAS ATÍPICAS NA ARENA POLÍTICA DA REVISÃO JUDICIAL
}

\author{
Ernani Carvalho, Luis Felipe Andrade Barbosa e José Mário Wanderley Gomes Neto
}

THE BRAZILIAN BAR ASSOCIATION AND ITS ATYPICAL INSTITUTIONAL PREROGATIVES IN THE JUDICIAL REVIEW ARENA

\section{RESUMO}

A LITERATURA POLÍTICA TEM RESSALTADO RELEVANTES ASPECTOS A RESPEITO DA JUDICIALIZAÇÃO DA POLÍTICA NO CENÁRIO BRASILEIRO. O PRESENTE ARTIGO DEBRUÇA-SE SOBRE UMA DE SUAS NUANCES, AO TRATAR SOBRE O PAPEL DA ORDEM DOS AdVOGADOS DO BRASIL (OAB) FRENTE À REVISÃO JUDICIAL ABSTRATA. DIFERENTEMENTE DOS DEMAIS ATORES DO SELETO ROL PRESENTE NO ARTIgo 103 da ConstituiçÃo FEderal, A OAB TEM A SUA ATUAÇÃO PAUTADA EM TRÊS PILARES, LEGITIMADOS PELO STF NO JULGAMENTO DA ADI 3.026/DF: AUSÊNCIA DE PERTINÊNCIA TEMÁTICA E DE CONTROLE EXTERNO E CARACTERIZAÇÃO como Serviço público independente. Percebe-Se, Assim, QUE O DESENHO INSTITUCIONAL BRASILEIRO CONFERIU À OAB UM ROL DE PRERROGATIVAS ATÍPICAS, SINALIZANDO PARA UM FORTE PODER POLITICO, CAPAZ DE GERAR CUSTOS E DIRECIONAR a agenda de políticas dos Poderes Públicos. Neste sentido, QUAIS OS INTERESSES E QUAL A PERFORMANCE DESTE ATOR NO CAMPO DA REVISÃO JUDICIAL ABSTRATA? ESTA PESQUISA PRETENDE RESPONDER A ESTA PERGUNTA POR MEIO DA ANÁLISE DE DADOS SOBRE AS AÇÕES DIRETAS DE INCONSTITUCIONALIDADE (ADI) E DA BUSCA DE EVIDÊNCIAS EMPÍRICAS SOBRE O PAPEL DESEMPENHADO PELA OAB NA ARENA POLÍTICA DA REVISÃO JUDICIAL. DE FORMA GERAL, COMO CONCLUSÃO, VERIFICOU-SE QUE HÁ UMA MAIOR TAXA DE SUCESSO DAS AÇÕES QUE VERSAM SOBRE INTERESSE CORPORATIVO, VALENDO-SE DAS QUESTÕES DE INTERESSE PÚBLICO VISANDO O SEU PRÓPRIO FORTALECIMENTO.

\section{PALAVRAS-CHAVE}

ORdEM dOS AdVOGAdOS dO BRASIL; JUdICIALIZAÇÃO DA POLÍTICA; AÇÕES DIRETAS DE INCONSTITUCIONALIDADE.

\begin{abstract}
THE POLITICAL LITERATURE HAS HIGHLIGHTED RELEVANT ASPECTS REGARDING THE LEGALIZATION OF POLITICS IN THE BRAZILIAN SCENARIO. THIS ARTICLE FOCUSES ON ONE OF ITS NUANCES, TO TREAT ABOUT THE ROLE OF THE BRAZILIAN BAR ASSOCIATION (OAB) FRONT OF ABSTRACT JUDICIAL REVIEW. UNLIKE THE OTHER PLAYERS IN THIS SELECT GROUP OF ARTICLE 103 of THE FEDERAL CONSTITUTION, THE OAB HAS ITS OPERATIONS BASED ON THREE PILLARS, LEGITIMIZED BY THE SUPREME COURT IN THE TRIAL OF ADI 3.026/DF: THE ABSENCE OF THEMATIC RELEVANCE, LACK OF EXTERNAL CONTROL AND CHARACTERIZATION AS INDEPENDENT PUBLIC SERVICE. IT IS CLEAR, THEREFORE, THAT THE INSTITUTIONAL DESIGN OF THE BRAZILIAN BAR ASSOCIATION GAVE A LIST OF ATYPICAL PREROGATIVES, SIGNALING A STRONG POLITICAL POWER, CAPABLE OF GENERATING SIGNIFICANT COSTS ON PUBLIC AUTHORITIES. IN THIS SENSE, WHAT INTERESTS AND WHAT THE PERFORMANCE OF THIS ACTOR IN THE FIELD OF ABSTRACT JUDICIAL REVIEW? THIS RESEARCH AIMS TO ANSWER THIS QUESTION BY EXPLORING A LARGE DATASET OF CONSTITUTIONAL ACTIONS (ADI) AND SEARCHING FOR EMPIRICAL EVIDENCE OF THE ROLE PLAYED BY BRAZILIAN OAB IN POLITICAL JUDICIAL REVIEW ARENA. OVERALL, IN CONCLUSION, IT WAS FOUND THAT THERE IS A HIGHER SUCCESS RATE OF THE ACTIONS THAT DEAL WITH CORPORATE INTERESTS, TAKING ADVANTAGE OF THE PUBLIC INTEREST AIMED AT STRENGTHENING ITSELF.
\end{abstract}

\section{KEYWORDS}

BRAZILIAN BAR ASSOCIATION; JUDICIALIZATION OF POLITICS; CONSTITUTIONAL ACTIONS. 


\section{INTRODUÇÃO: JUDICIALIZAÇÃO DA POLÍTICA E REVISÃO JUDICIAL}

Em linhas gerais, a judicialização da política é um termo que vem sendo utilizado para expressar o fenômeno de expansão do Poder Judiciário sobre questões que, a priori, não lhe diriam respeito (TATE; VALINDER, 1995). Neste sentido, a expressão denota um movimento de crescimento, de alargamento da esfera judicial no controle das atividades estatais, de modo a adentrar outras esferas de poder.

Para Hirschl (2004), a judicialização é consequência do novo constitucionalismo que tem origem no pós-Segunda Guerra, devendo ser entendida como um passo progressista rumo à igualdade, à justiça distributiva e ao controle sobre governos excessivamente partidários.

Tate e Vallinder (1995) elencam algumas características do fenômeno em abordagem, buscando esmiuçar o sentido do mesmo. Assim, seria este uma influência e ingerência judiciais em arenas políticas, onde o Judiciário não reside normalmente; uma transferência do decision-making do Legislativo e do Executivo para o Judiciário; e, por fim, uma transformação de uma deliberação política em uma decisão judicial.

Hirschl (2008) também analisa a natureza e o alcance do novo nível da política judicializada, bem como apresenta estudos recentes que avançam no sentido de fornecer uma explicação realista sobre o fenômeno em tela. Aponta, assim, uma construção baseada em três níveis de judicialização, iniciando pela expansão no que concerne à determinação das políticas públicas, passando pela ampliação do alcance da fiscalização administrativa do Judiciário, por meio da proliferação de agências administrativas no Estado social moderno, e chegando à atribuição de confiança a juízes e tribunais para lidar com as questões atinentes à megapolítica.

Como consequência desta construção, houve a transformação das Cortes Supremas (ouTribunais Constitucionais), em boa parte das democracias ocidentais, em instituições-chave para a formulação e implementação de políticas públicas (GINSBURG, 2003; SWEET, 2000). Ademais, o Judiciário passa a atuar em vários tipos de controvérsias, desde questões atinentes ao processo democrático, às prerrogativas dos outros Poderes, a corroboração na mudança do regime ou mesmo na definição da identidade coletiva.

Hirschl (2008) pontua ainda que a expansão judicial não pode ser compreendida separadamente das lutas políticas, sociais e econômicas que formam um determinado sistema político. É também fundamental considerar os determinantes políticos do comportamento e do empoderamento judicial e a interação entre as esferas política e judicial.

Quanto à sua operacionalização, o Poder Judiciário vale-se, especialmente, do instituto do controle de constitucionalidade. Em termos gerais, este controle significa a possibilidade de se recorrer a um juízo ou tribunal caso haja a interpretação de não atendimento ao que está presente na Constituição.

Como é de conhecimento geral, no Brasil, este instituto funciona de forma híbrida, podendo ser concentrado ${ }^{1}$ ou difuso, ${ }^{2}$ o que aumenta, pelo menos no aspecto do desenho institucional, a possibilidade de uma intervenção judicial. ${ }^{3}$ 
A literatura brasileira tem explorado diversos aspectos deste processo (TAYLOR, 2008; ARANTES, 2009; CARVALHO, 2009). Neste artigo abordaremos uma pequena, embora significativa parcela, deste imenso e complexo iceberg, que é a relação litigiosa entre Estado e Sociedade.

Nosso interesse principal é investigar o papel de um dos atores legitimados para propor ação direta de inconstitucionalidade (ADI), presentes no rol taxativo do artigo 103 da Constituição Federal, no qual se encontra, no seu inciso VII, o Conselho Federal da Ordem dos Advogados do Brasil.

Embora outros atores, como as Uniões Sindicais de âmbito nacional e Mesas do Senado e da Câmara dos Deputados, tenham o dever de justificar a existência de um nexo formal entre a sua natureza e a questão política objeto de disputa (pertinência temática, em termos técnicos), o Conselho Federal da Ordem dos Advogados do Brasil (OAB) tem a prerrogativa constitucional para propor as ações constitucionais sobre qualquer tema de disputa política. Então, resta saber: qual é a relevância das ações constitucionais da Ordem dos Advogados do Brasil no cenário da judicialização da política? Qual o papel desempenhado pela OAB na arena política da revisão judicial? A entidade busca, ao provocar demandas no STF via revisão judicial abstrata, o fortalecimento dos seus próprios interesses? Este artigo pretende responder a estas perguntas por meio de uma análise empírica com base no banco de dados sobre as ações diretas de inconstitucionalidade (ADIs) disponível no sítio do Supremo Tribunal Federal. ${ }^{4}$

\section{OAB E AS PRERROGATIVAS ATÍPICAS}

Parece ser relevante observar, em termos políticos, as implicações da ausência de pertinência temática para a OAB. Mesmo se enquadrando como entidade de classe de âmbito nacional, o Conselho Federal da OAB foi contemplado com a legitimação para propositura da ADI em um inciso próprio, aliada à sua caracterização como legitimado ativo universal. Desta forma, o Conselho pode, diferentemente de outras entidades de classe de âmbito nacional, propor ADI sobre qualquer matéria em que se alegue vício de inconstitucionalidade.

Tal ampliação dos legitimados ativos, a qual gerou a inclusão do Conselho Federal da $\mathrm{OAB}$ e a consequente legitimação universal, deve-se, na perspectiva jurídica, à previsão constitucional do artigo 133 da Constituição Federal, a qual salienta que o advogado é indispensável à administração da justiça. ${ }^{5}$

Outra particularidade interessante é que, mesmo possuindo característica de uma instituição do direito público, forjada em lei como autarquia federal, a Ordem dos Advogados do Brasil não se sujeita aos ditames impostos à Administração Pública direta e indireta. O próprio Estatuto da Advocacia e da Ordem dos Advogados do Brasil (Lei n. 8.906/94) estabelece, no artigo 44, o seu caráter público e sua independência 
funcional, indicando como uma de suas finalidades principais a defesa da Constituição, dos direitos humanos e da ordem jurídica do Estado democrático de direito, além da promoção da representação e defesa dos advogados no país. ${ }^{6}$

Diante dos pontos ressaltados, fica claro que a entidade não se submete às regras do regime jurídico administrativo, ou seja, não se submete a qualquer tipo de controle externo.

Não obstante à previsão legal, o STF, ao julgar a ADI 3.026/DF, ${ }^{7}$ reconheceu adicionalmente que a OAB se caracteriza como um "serviço público independente", reforçando ainda que não está sujeita a controle da Administração, nem está vinculada a qualquer de suas partes.

Portanto, percebemos que dentre os legitimados presentes no rol do artigo 103 da Carta Magna, pode-se considerar que o Conselho Federal da Ordem dos Advogados do Brasil sobressai-se como um dos mais poderosos atores, por reunir a falta de limitação no que diz respeito ao seu campo temático com a ausência de controle estatal direto. Isto significa que a $\mathrm{OAB}$ possui a prerrogativa de propor $\mathrm{ADI}$ sobre qualquer tema que impere dúvida a respeito da sua constitucionalidade.

Por outro lado, os demais atores, que possuem a chamada legitimação ativa universal, fazem parte dos Poderes Públicos constituídos, à exceção dos partidos políticos com representação no Congresso Nacional. Desta forma, a OAB, como entidade de classe, detém, por meio do seu Conselho Federal, prerrogativas que vão além daquelas concedidas aos demais atores políticos de âmbito privado, bem como a alguns atores de caráter essencialmente público, presentes no rol supramencionado.

Conforme já pontuado, não há dúvidas de que a Ação Direta de Inconstitucionalidade se constitui em um mecanismo de extrema importância para a defesa da cidadania e para a racionalização da Administração Pública, contribuindo, por conseguinte, para a efetivação da justiça em um Estado democrático de Direito (CARVALHO, 1999). Contudo, conforme ressaltado pela literatura política (TAYLOR, 2008; CARVALHO, 2010), percebemos que a prerrogativa de propor esta ação gerou para aquele rol de atores um poder político evidente. E, no caso específico da OAB, gerou um poder político sem precedentes, devido ao seu amplo raio de ação e à inexistência de mecanismos de controle, uma vez que a instituição não possui, pelo menos em tese, relação direta com os Poderes Públicos constituídos.

Estamos diante de uma entidade de âmbito nacional que possui feições públicas, é entendida como serviço público, mas cuja atuação é pautada segundo ditames privados, diante de sua independência política frente aos Poderes constituídos. Ou seja, sua lógica de atuação política é, pelo menos em tese, diversa dos outros legitimados ativos.

Em síntese, o Conselho Federal da Ordem dos Advogados do Brasil atua no Supremo Tribunal Federal, mediante as ações diretas de inconstitucionalidade, segundo três bases fundamentais: 
1) ausência de pertinência temática; ${ }^{8-9}$

2) ausência de controle externo; ${ }^{10-11}$

3) caracterização como serviço público independente.

Ao que tudo indica, diante dos elementos apontados, sua legitimidade para se valer amplamente deste instrumental fundamental à democracia brasileira vincula-se à proteção de interesses públicos e, residualmente, à manutenção das prerrogativas de atuação dos advogados. Entretanto, qual será o raio de atuação da OAB quando provoca a Corte Constitucional?

O fato de o Conselho Federal da OAB possuir como incentivo institucional a formatação híbrida, de contornos públicos e de atuação privada, aliado à falta de limitação no que diz respeito ao seu campo temático - possui a prerrogativa de propor ADI sobre qualquer tema que impere dúvida a respeito de sua constitucionalidade, visto que tem interesse em preservar a supremacia da Constituição por força de suas próprias atribuições institucionais (CLÈVE, 1995; LOURENÇO, 1998) - bem como à falta de controle estatal sobre a sua atuação, acabou por transformá-lo, na nossa concepção, em um dos atores politicamente mais privilegiados do processo de interpretação da Constituição.

Embora a $\mathrm{OAB}$ seja um conselho de classe responsável por regular a profissão de advogado, é ingênuo não se considerar e enquadrar a entidade como um grupo de interesse, visto que possui a prerrogativa de levar questões para serem processadas pelo sistema político (SANTOS, 2011), a exemplo da própria discussão sobre a constitucionalidade de leis ou atos normativos no âmbito do STF. Ocorre que a construção legal e jurisprudencial brasileira aponta para uma estratégia de convencimento, na qual a função principal desta entidade é prestar um serviço público. ${ }^{12}$

Há que se ponderar aqui que este processo de alocação da OAB no plano constitucional brasileiro é percebido pelos autores como consequência de um desenho constitucional altamente garantidor. Uma das preocupações fundamentais do constituinte de 1988 foi garantir, no plano institucional, barreiras à um retrocesso autoritário. Ocorre que, diferentemente de outros países latino-americanos, no Brasil, a construção destas garantias institucionais elegeu a OAB, o Ministério Público e o Judiciário, entre outros, como peças essenciais para o bom funcionamento da democracia.

Esta especificidade brasileira é tão gritante que o próprio texto constitucional atribui aos advogados o caráter essencial à administração da justiça. Entre os seus dispositivos, a Constituição brasileira faz alusão ao termo advogado ${ }^{13} \mathrm{em} 23$ momentos distintos. Se comparado a países que passaram por um processo similar de redemocratização no mesmo período histórico, como Argentina (3 alusões) e Chile (14 alusões), este fato é extremamente significante e sinaliza para a importância dada pela Constituição Federal de 1988 ao papel do advogado como agente de manutenção do contexto democrático brasileiro. 
A tabela abaixo aponta a relação de países sul-americanos e a quantidade de alusões à terminologia "advogado(s)" em seus textos constitucionais:

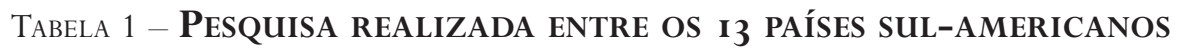
na Political Database of the americas, do Centro de Estudos PARA AMÉRICA LATINA DA GEORGETOWN UNIVERSITY

\begin{aligned} & PAISES ALUSÕES CONSTITUCIONAIS AO(S) TERMO(S) “ADVOGADO(S)” \\ & \hline ARGENTINA 3 \\ & \hline BOLÍVIA 2 \\ & \hline BRASIL 23 \\ & \hline CHILE 14 \\ & \hline COLÔMBIA 6 \\ & \hline EQUADOR 11 \\ & \hline GUIANA 1 \\ & \hline GUIANA FRANCESA N/A \\ & \hline PARAGUAI 5 \\ & \hline PERU 6 \\ & \hline SURINAME 0 \\ & \hline URUGUAI 2 \\ & \hline VENEZUELA 3 \\ & \hline\end{aligned}

Fonte: <http://pdba.georgetown.edu/>.

Contudo, como compreender a participação da OAB neste processo sem levar em consideração os seus próprios interesses, principalmente no que diz respeito à preservação do seu status quo e a ampliação de sua influência política? É ingênuo considerar uma atuação da entidade voltada para o interesse público, completamente dissociada de seus interesses corporativos.

Diante desta problemática, é indispensável trazer ao debate a teoria sobre os grupos de interesse. Ao discorrer sobre a Teoria Democrática Pluralista, Dahl (1956) 
percebe que os recursos que contribuem para o poder estão distribuídos entre diferentes grupos. O poder é partilhado entre grupos governamentais e interesses externos que exercem pressão sobre eles. No caso em análise, percebemos a presença de um grupo externo à esfera de governo detentor de um forte instrumental político, que viabiliza substancialmente a representação de seus interesses no processo político.

Uma das construções teóricas sobre a articulação de interesses, proposta por Salisbury (1975), aponta que os grupos podem ser vistos como (I) unidades de inputs; (II) como outputs do sistema político; (III) como authorizative decision makers; ou (IV) como organizações. Enquanto unidades de inputs, os grupos de interesse são componentes que oferecem um grande número de demandas para os decisionmakers. Cabe destacar que o Conselho Federal da Ordem dos Advogados do Brasil se perfaz como uma organização de excelência no que concerne à atividade de provocar o Poder Judiciário, sendo detentora do saber jurídico quanto ao instrumental utilizado e quanto à própria argumentação jurídica.

Dentro deste enfoque, Santos (2011) salienta o trabalho de Almond e Powell (1966) acerca da tipologia dos grupos de interesse, os quais são divididos em quatro tipos:

(1) Anomic interest groups - grupos espontâneos, que se formam repentinamente por reações individuais a uma determinada questão;

(2) Nonassociational groups - grupos sem constituição formal e raramente bem organizados, exercendo atividades pontuais e esporádicas, com interesses e, porventura, identidade em comum;

(3) Institutional groups - grupos formalmente constituídos, nos quais seus integrantes possuem funções sociais e políticas variadas;

(4) Associational groups - grupos formados especificamente para representar os interesses de seus membros.

No que tange a esta classificação, a Ordem dos Advogados do Brasil, nosso objeto de estudo, é um exemplo híbrido de associational group e institutional groups, visto que a entidade foi idealizada para representar os interesses dos advogados e fiscalizar a atividade profissional, mas, também, tem como missão a defesa da Constituição, dos direitos humanos e da ordem jurídica do Estado democrático de direito, tendo como uma de suas atribuições típicas provocar o processamento de demandas pelo sistema político. E um dos canais utilizados para tal processamento é o Poder Judiciário.

Ao tratar sobre o sistema de representação de interesses no Brasil, o autor em questão salienta a importância da análise do contexto institucional para uma correta 
dimensão dos resultados políticos obtidos pelos diversos grupos. A partir da releitura dos trabalhos de Diniz e Boschi (1999), concebe tal representação de interesses de maneira híbrida, caracterizada pela existência de diversos padrões, donde se ressaltam a persistência do corporativismo tradicional, amplamente presente antes do processo de redemocratização, o desenvolvimento de grupos organizados segundo a lógica pluralista, bem como o surgimento do neocorporativismo como alternativa de participação dos grupos privados em certas arenas de decisão. Santos (2011) destaca que:

Nesse processo decisório o Executivo, o Legislativo e o Judiciário passam a ser canais privilegiados para a vocalização dessas demandas e passam a ser arenas estratégicas para colocar essas demandas na agenda política. Essas demandas, portanto, acontecem num determinado contexto institucional e político e é de se esperar que seu padrão de interação, sua eficiência e seu sucesso dependam não apenas do vigor das organizações, mas também do ambiente institucional sob o qual suas demandas serão recepcionadas (como inputs) e tratadas no processo decisório.

Ao analisar a atuação dos grupos de interesse no Judiciário norte-americano, Neubauer et al (2010) salientam que os grupos de interesse direcionam seus esforços ao Judiciário para promover políticas públicas que favoreçam os seus membros. Assim, regularmente levam causas ao tribunal especificamente para desenvolver doutrinas jurídicas para sua causa.

Ocorre que, paralelamente à discussão de questões corporativas, próprias da entidade, a OAB foi contemplada com um rol de atribuições atípicas, associadas a uma atuação voltada essencialmente ao interesse público. Neste sentido, a OAB pode se valer politicamente do Poder Judiciário para provocar decisões sobre questões públicas e/ou corporativas, de seu interesse direto. ${ }^{14}$

Diante destes apontamentos, a grande questão percebida no Brasil, em termos de revisão judicial concentrada, é que o Conselho Federal da Ordem dos Advogados do Brasil se constitui como um ator institucional que ganhou um rol de prerrogativas atípicas, diretamente associadas à atuação pública. Desta forma, diante desta construção legal observada no país, torna-se extremamente importante verificar a racionalidade da $\mathrm{OAB}$ quanto à dimensão política das ADIs propostas no Supremo Tribunal Federal.

\section{OAB NA ARENA POLÍTICA DA REVISÃO JUDICIAL}

No contexto da revisão judicial abstrata, a ação direta de inconstitucionalidade (ADI) corporifica-se como o principal mecanismo de atuação jurídica (MENDES, 2011), inclusive diante do número expressivo de ações propostas, se comparada aos demais 
mecanismos, consubstanciados na ação declaratória de constitucionalidade (ADC), na arguição de descumprimento de preceito fundamental (ADPF) e na ação direta de inconstitucionalidade por omissão (ADO). ${ }^{15}$

Relativamente à atuação política, a ação direta de constitucionalidade proporciona a discussão sobre a constitucionalidade de leis e atos normativos federais e estaduais dos Poderes Públicos, incluindo atos do próprio Poder Judiciário. Portanto, representa um instrumento fortíssimo de controle político dos atos destes poderes. ${ }^{16}$

A partir de um banco de dados produzido pelos autores, o qual engloba cerca de 4.300 ações diretas de inconstitucionalidade propostas até o mês de julho de 2009, percebe-se que o Conselho Federal da OAB possui uma significativa taxa de sucesso, ${ }^{17}$ correspondente a $75 \%$ de ações julgadas.

As frequências obtidas neste banco apontam que o ator em questão propôs um total de 177 ADIs, das quais 86 foram julgadas e 91 ainda aguardam julgamento. Dentre o universo de ações propostas, 24 foram julgadas procedentes, seja na sua totalidade ou parcialmente. Ou seja, do total de ações propostas pela OAB e apreciadas pelo STF, 75\% foram objeto de decisão, seja em sede liminar ou de mérito.

\section{TABEla 2 - FreQUÊNCIAS DAS AÇÕES DIRETAS DE INCONSTITUCIONALIDADE PROPOSTAS ATÉ JULHO DE 2009}

\begin{tabular}{|c|c|c|c|c|c|c|c|}
\hline & PROCEDENTE & $\begin{array}{l}\text { PROCEDENTE } \\
\text { EM PARTE }\end{array}$ & IMPROCEDENTE & PREJUDICADA & $\begin{array}{l}\text { NÃO CONHECIDA/ } \\
\text { NEGADO } \\
\text { SEGUIMENTO }\end{array}$ & $\begin{array}{l}\text { AGUARDANDO } \\
\text { JULGAMENTO }\end{array}$ & \\
\hline PRESIDENTE & & & & & & & \\
\hline DA REPÚBLICA & 0 & 0 & 1 & 0 & 0 & 5 & 6 \\
\hline \multicolumn{8}{|l|}{ MESA DIRETORA } \\
\hline FEDERAL & 0 & 0 & 0 & 0 & 0 & 1 & 1 \\
\hline \multicolumn{8}{|l|}{$\begin{array}{r}\text { MESA DIRETORA } \\
\text { DE ASSEMBLEIA } \\
\text { LEGISLATIVA OU } \\
\text { DA CÂMARA }\end{array}$} \\
\hline DISTRITAL DO DF & 2 & 1 & 3 & 13 & 16 & 11 & 46 \\
\hline \multicolumn{8}{|l|}{ GOVERNADOR } \\
\hline OU DO DF & 287 & 56 & 47 & 162 & 105 & 418 & 1075 \\
\hline \multicolumn{8}{|l|}{$\begin{array}{r}\text { PROCURADOR- } \\
\text { GERAL DA }\end{array}$} \\
\hline REPÚBLICA & 226 & 44 & 21 & 178 & 74 & 361 & 904 \\
\hline \multicolumn{8}{|l|}{$\begin{array}{l}\text { CONSELHO } \\
\text { FEDERAL DA } \\
\text { ORDEM DOS } \\
\text { ADVOGADOS }\end{array}$} \\
\hline DO BRASIL & 18 & 6 & 8 & 40 & 14 & 91 & 177 \\
\hline
\end{tabular}


: OAB E AS PRERROGATIVAS ATÍPICAS NA ARENA POLÍTICA DA REVISÃo JUDICIAL

\begin{tabular}{|c|c|c|c|c|c|c|c|}
\hline $\begin{array}{r}\text { PARTIDO } \\
\text { POLITICO COM } \\
\text { REPRESENTACCÃO } \\
\text { NO CONGRESSO } \\
\text { NACIONAL }\end{array}$ & 61 & 27 & 47 & 227 & 235 & 224 & 821 \\
\hline $\begin{array}{r}\text { CONFEDERACCÃO } \\
\text { SINDICAL OU } \\
\text { ENTIDADE DE } \\
\text { CLASSE DE } \\
\text { ÂMBITO NACIONAL }\end{array}$ & 76 & 28 & 38 & 159 & 287 & 420 & 1008 \\
\hline $\begin{array}{r}\text { NÃO É PARTE } \\
\text { LEGÍTIMA }\end{array}$ & 0 & 0 & 3 & 7 & 217 & 11 & 238 \\
\hline TOTAL GERAL & 670 & 162 & 168 & 786 & 948 & 1542 & 4276 \\
\hline
\end{tabular}

Em termos absolutos, considerando-se as variáveis apontadas, a taxa de sucesso supramencionada só é menor que as obtidas pelo Procurador-Geral da República e pelos Governadores de Estado ou do Distrito Federal (92,78\% e 87,95\%, respectivamente).

\section{TABela 3 - TAXA DE SUCESSO DAS AÇÕES DiRETAS} DE INCONSTITUCIONALIDADE PROPOSTAS

\begin{tabular}{ll} 
PROCURADOR-GERAL DA REPÚBLICA & $92,78 \%$ \\
\hline GOVERNADOR DE ESTADO OU DF & $87,95 \%$ \\
\hline CONSELHO FEDERAL DA OAB & $75 \%$ \\
\hline
\end{tabular}

O significativo aproveitamento na adjudicação constitucional, mediante ausência de pertinência temática, associado à sua condição institucional pública e ausência de controle estatal, torna o Conselho Federal da Ordem dos Advogados do Brasil um ator privilegiado na arena política da revisão judicial abstrata. Não há amarras institucionais que possam limitar a atuação da $\mathrm{OAB}$ no que tange a revisão judicial abstrata.

Conforme ressaltado inicialmente, um dos objetivos do presente estudo é saber qual a relevância das ações constitucionais da Ordem dos Advogados do Brasil no cenário da judicialização da política. Qual o papel desempenhado pela OAB na arena política da revisão judicial abstrata?

Como nos voltamos à análise sobre o campo de interesse de um dos atores com a prerrogativa de propor este tipo de ação - o Conselho Federal da Ordem dos Advogados do Brasil -, nada mais lógico do que se valer das ADIs propostas no STF, de 
forma a se pontuar quais são as matérias que a $O A B$ vem discutindo em sede do Tribunal Constitucional.

Entretanto, em primeiro lugar, faz-se necessário conceituar interesse público e interesse corporativo. Em linhas gerais, o interesse público corresponde aos interesses qualificados como próprios da sociedade (MELLO, 2006). Significa a vontade da maioria dos seres que vivem em sociedade, ou seja, o somatório dos interesses individuais destes, desde que este somatório represente a vontade da maioria (MARINELA, 2011). Entende-se, ainda, o interesse público como o interesse nacional no âmbito interno, representando a generalidade dos habitantes de um país, cujo interesse se contrapõe aos interesses particulares de cada um dos cidadãos e de cada um dos grupos econômico-sociais (BOBBIO et al, 2004).

Quanto ao interesse corporativo, consideramos, no cenário da adjudicação constitucional, como aquele que se volta à maximização dos ganhos para o grupo. Ou seja, o grupo procura as arenas de decisão política objetivando a promoção dos seus próprios interesses. De forma residual, partindo da construção de Bobbio et al (2004), podemos considerá-lo como aquele que se volta aos interesses de cada um dos grupos econômico-sociais existentes.

Diante do objeto de análise do presente trabalho, foi construído um banco de dados com as ações diretas de inconstitucionalidade propostas pelo Conselho Federal da OAB até o mês de julho de 2012, o qual totaliza o número de 238 ADIs. ${ }^{18}$

Considerando-se a ótica de sua propositura, dividimos primeiramente as ADIs entre as variáveis interesse público e interesse corporativo. Também foram considerados os dados atinentes ao julgamento das ADIs, dividindo-as entre as seguintes variáveis: procedente; procedente em parte; improcedente; prejudicada; não conhecida/negado seguimento; aguardando julgamento, conforme o resultado final apresentado pelo Supremo Tribunal Federal.

No que tange à caracterização do interesse corporativo, consideramos todas as ações em que era perceptível uma demanda direcionada ao fortalecimento das prerrogativas dos advogados ou atinente à sua atuação profissional. Várias ações foram consideradas de interesse corporativo, não obstante a sua construção e fundamentação ser vinculada ao interesse público. ${ }^{19}$

A partir deste critério, diante do universo de ações propostas pelo Conselho Federal da OAB, 91 ações versam sobre interesse corporativo, ou seja, versam sobre temas que dizem respeito aos interesses dos seus próprios membros, perfazendo um total de apenas 38\%. Por outro lado, um total de 147 ações trazem em seu bojo uma discussão voltada ao interesse público, representando $62 \%$ do universo $(\mathrm{N})$ de ações propostas. $^{20}$ 
080 : OAB E AS PRERROGATIVAS ATÍPICAS NA ARENA POLÍTICA DA REVISÃO JUDICIAL

Gráfico 1 - Percentual De interesse Corporativo
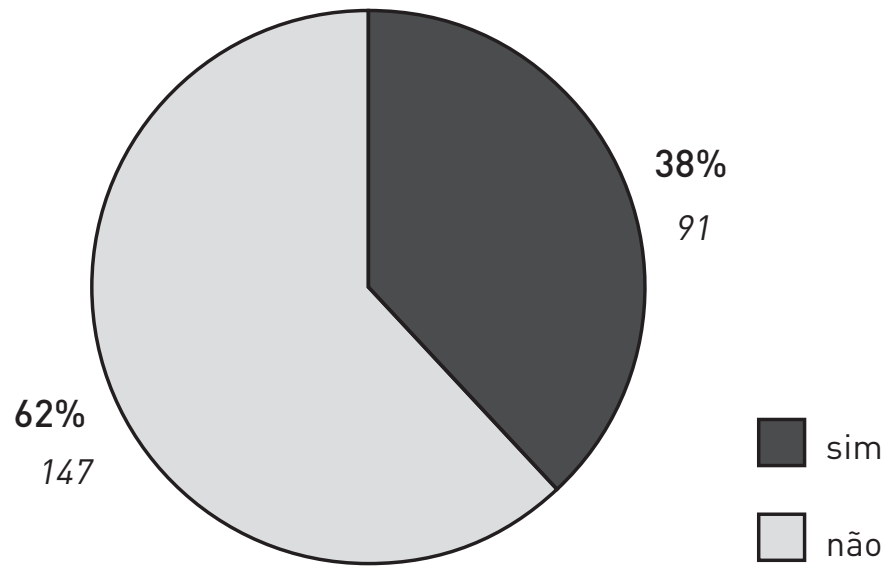

Gráfico 2 - Resultado Final das ADis propostas pelo Conselho FEDERAL DA OAB

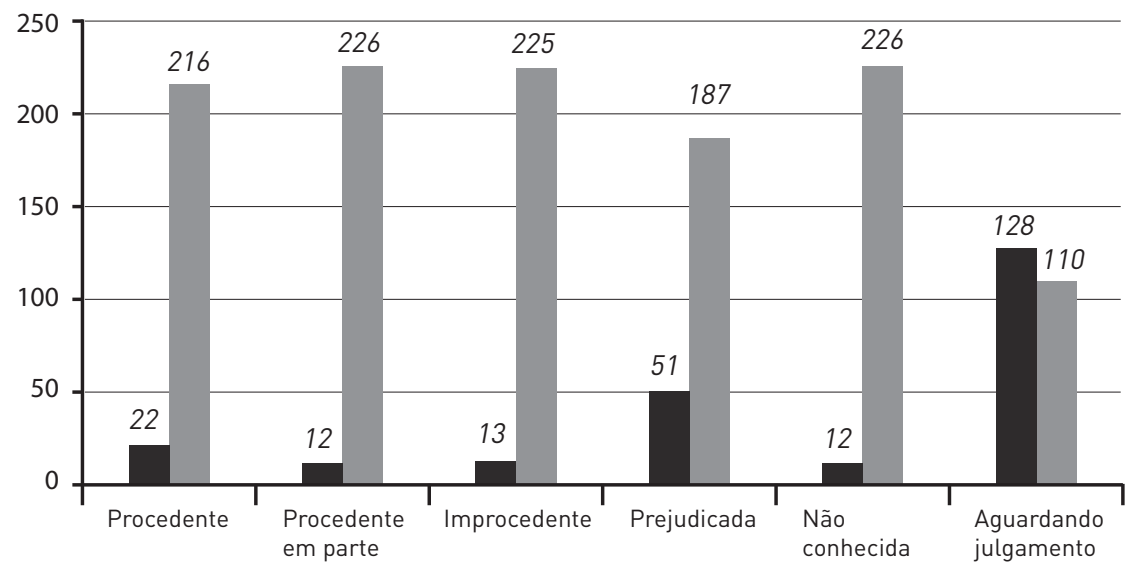

$\operatorname{sim}$

não 
Para análise do resultado final, imputamos relevante considerar a taxa de sucesso do CFOAB frente as ações propostas. No que se refere à taxa de sucesso, levouse em consideração apenas as ações objeto de decisão de mérito, conforme referenciado acima. Desta forma, para a sua caracterização, foram computados os número totais das ações que atinam à procedência, procedência em parte e improcedência. As ações prejudicadas são desconsideradas por não ser objeto de decisão, diante da existência de um impedimento formal ou material, como a hipótese de perda do objeto (extinção da lei ou modificação dos dispositivos atacados pela ADI).

Como resultado final, levando-se em consideração o mérito das ações, observase que 47 ações foram objeto de decisão final de mérito. Paralelamente, 51 ações restaram prejudicadas, enquanto 12 não foram conhecidas/negado seguimento e 128 ainda aguardam julgamento. Estes dados apontam para uma considerável taxa de sucesso, representando o percentual de 72,3\% das ações julgadas.

Considerando-se o recorte temporal, percebemos que a partir do ano de 2000 há uma mudança significativa no conteúdo das ações propostas pelo Conselho Federal da OAB. Verifica-se na Tabela 4 que, até o ano de 1999, do total de 76 ações diretas de inconstitucionalidade propostas, 39 ações versavam sobre interesse corporativo, representando o percentual de 51,36\%. Entre os anos de 2000 a 2012 , do total de 162 ações propostas, apenas 52 versavam sobre interesse corporativo, significando apenas 32,09\%.

TABela 4 - Relação ENTRE O NúMERO DE AÇÕES PROPOSTAS

E O PERCENTUAL RELATIVO AO INTERESSE CORPORATIVO

\begin{tabular}{rll} 
PERÍODO & NÚMERO DE ADIS PROPOSTAS & INTERESSE CORPORATIVO $(\%)$ \\
\hline 1989 A 1999 & 76 & $39(51,36 \%)$ \\
\hline 2000 A 2012 & 162 & $52(32,09 \%)$ \\
\hline TOTAL & 238 & $91(38,23 \%)$ \\
\hline
\end{tabular}




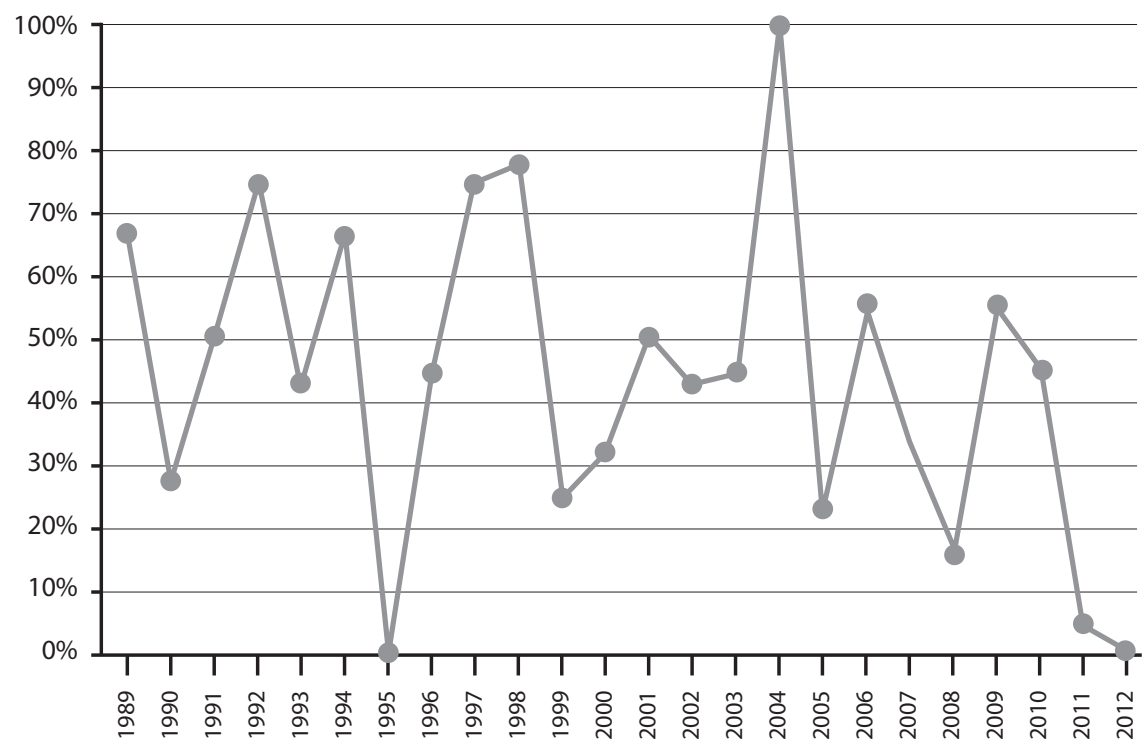

O Gráfico 3 mostra claramente como os percentuais relativos ao interesse corporativo são menores a partir do ano de 2000, mesmo diante do grande número de ações propostas pelo Conselho Federal da OAB. O único momento excepcional deste recorte temporal é o ano de 2004, quando se visualiza o percentual de 100\% para interesse corporativo. Mesmo assim, no que tange a todo o período analisado, a cada três ações propostas pelo CFOAB, duas versam sobre interesse público.

TABEla 5 - FrequÊNCIAS DAS ADIs PROPOSTAS ENTRE OS ANOS DE I988 A I999

\begin{tabular}{|c|c|c|c|c|c|c|}
\hline $\begin{array}{r}\text { ADIS } \\
1988 \text { A } 1999\end{array}$ & PROCEDENTE & $\begin{array}{l}\text { PROCEDENTE } \\
\text { EM PARTE }\end{array}$ & IMPROCEDENTE & PREJUDICADA & $\begin{array}{l}\text { NÃO } \\
\text { CONHECIDA/ } \\
\text { NEGADO } \\
\text { SEGUIMENTO }\end{array}$ & $\begin{array}{l}\text { AGUARDANDO } \\
\text { JULGAMENTO }\end{array}$ \\
\hline $\begin{array}{r}\text { INTERESSE } \\
\text { CORPORATIVO }\end{array}$ & 3 & 4 & 4 & 19 & 4 & 5 \\
\hline \multicolumn{7}{|l|}{ INTERESSE } \\
\hline PÚBLICO & 4 & 2 & 5 & 16 & 3 & 7 \\
\hline TOTAL & 7 & 6 & 9 & 35 & 7 & 12 \\
\hline
\end{tabular}


TABela 6 - FrequênCIAS dAS ADIs PROPOSTAS ENTRE OS ANOS DE 2000 A JULHO DE 2012

\begin{tabular}{|c|c|c|c|c|c|c|}
\hline $\begin{array}{r}\text { ADIS } \\
2000 \text { A } 2012\end{array}$ & PROCEDENTE & $\begin{array}{l}\text { PROCEDENTE } \\
\text { EM PARTE }\end{array}$ & IMPROCEDENTE & PREJUDICADA & $\begin{array}{l}\text { NÃO } \\
\text { CONHECIDA/ } \\
\text { NEGADO } \\
\text { SEGUIMENTO }\end{array}$ & $\begin{array}{l}\text { AGUARDANDO } \\
\text { JULGAMENTO }\end{array}$ \\
\hline $\begin{array}{r}\text { INTERESSE } \\
\text { CORPORATIVO }\end{array}$ & 8 & 5 & 2 & 6 & 2 & 29 \\
\hline $\begin{array}{l}\text { INTERESSE } \\
\text { PÚBLICO }\end{array}$ & 7 & 1 & 2 & 10 & 3 & 87 \\
\hline TOTAL & 15 & 6 & 4 & 16 & 5 & 116 \\
\hline
\end{tabular}

As tabelas 5 e 6 apresentam as frequências das ADIs no recorte temporal supramencionado (1988 a 1999 e 2000 a 2012). Os dados mostram que a OAB possui uma maior taxa de sucesso nas ações que versam sobre interesse corporativo, nos dois momentos históricos apontados. No primeiro momento, relativo aos anos de 1988 a 1999 (Tabela 5), das 11 ADIs com decisão de mérito que tratam sobre interesse corporativo, 7 são consideradas procedentes ou procedentes em parte, contra 4 consideradas improcedentes, representando o percentual de 63,63\%. Já das 14 ADIs meritoriamente julgadas, que tratam sobre interesse público, apenas 6 são procedentes ou procedentes em parte, contra 5 consideradas improcedentes, representando o percentual de 54,54\%.

Quanto ao segundo momento, que se refere aos anos de 2000 a julho de 2012 (Tabela 6), das 15 ADIs com decisão de mérito e que versam sobre interesse corporativo, 13 são consideradas procedentes ou procedentes em parte, contra apenas 2 ações improcedentes. Estes números representam uma taxa de sucesso de 86,66\%. Por outro lado, das 10 ações que versam sobre interesse público, 8 são procedentes ou procedentes em parte, frente a 2 improcedentes. Tais números evidenciam uma taxa de sucesso de $80 \%$.

Outro dado extremamente relevante e que diferencia significativamente os dois momentos históricos é o relativo ao número de ADIs que aguardam julgamento. No primeiro momento, são 5 (cinco) ações sobre interesse corporativo e 7 sobre interesse público aguardando julgamento. Por seu turno, quanto ao segundo momento, são 29 ADIs sobre interesse corporativo e 87 sobre interesse público nesta situação.

Paralelamente, deve-se frisar o reduzido número de ADI versando sobre interesse corporativo nos dois últimos anos analisados. Em 2011, de 22 ações propostas, apenas 1 versa sobre interesse corporativo. No ano de 2012, considerando-se os dados coletados até o mês de julho, observa-se que, das 23 ações propostas, nenhuma delas 
versa sobre interesse corporativo. Estes dados revelam um número significativo de ações recentes que tratam sobre interesse público e que, em certa medida, deve ser considerado na análise.

Verifica-se também que, no período total analisado, das 22 ações julgadas procedentes, 15 delas se referem a ações propostas a partir do ano de 2000. Destas ações, 8 versam sobre interesse corporativo. O Gráfico 4 mostra percentuais significativos de ações julgadas procedentes, ano a ano, entre o período de 2002 a 2007.

\section{Gráfico 4 - Relação entre os ANOS E A PROCedênCIA do PEDIDO}

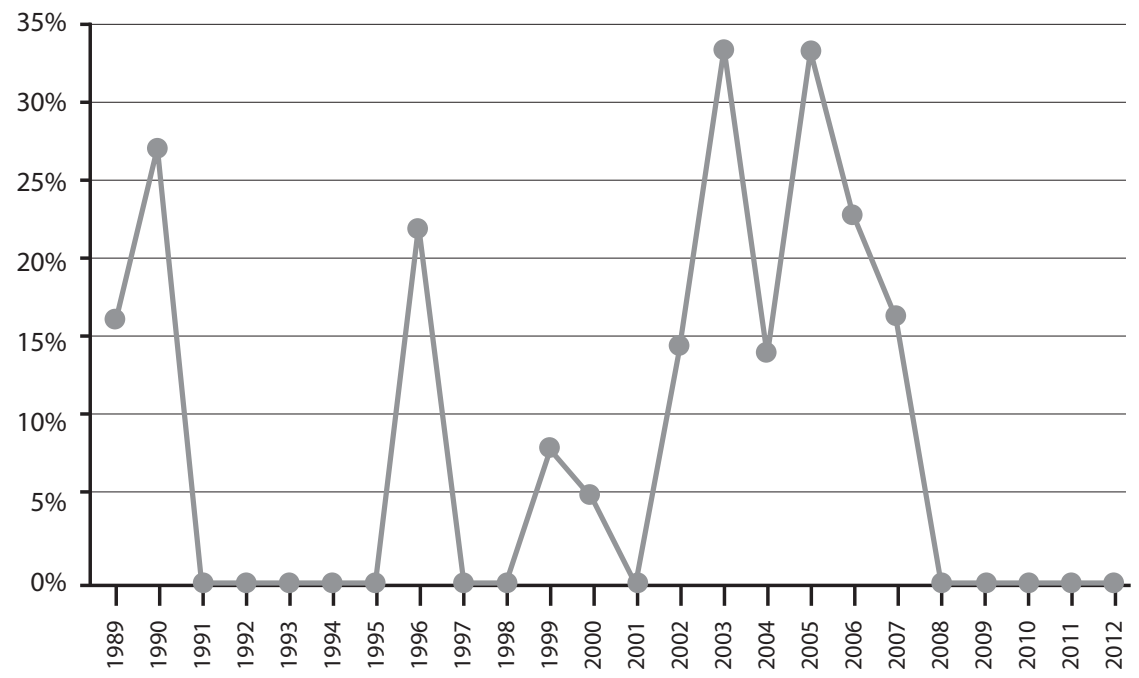


Gráfico 5 - RelaçÃo ENTRE OS ANOS E A PROCEDÊNCIA EM PARTE DO PEDIDO

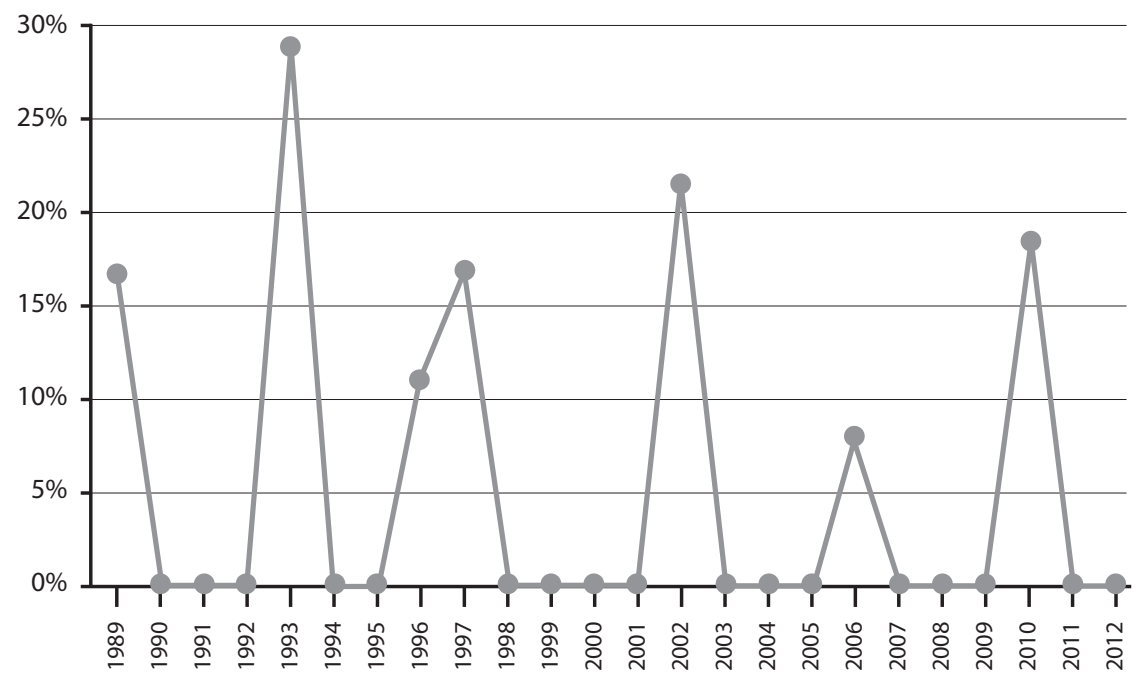

GrÁfico 6 - RELAÇÃO ENTRE OS ANOS E A IMPROCEDÊNCIA DO PEDIDO

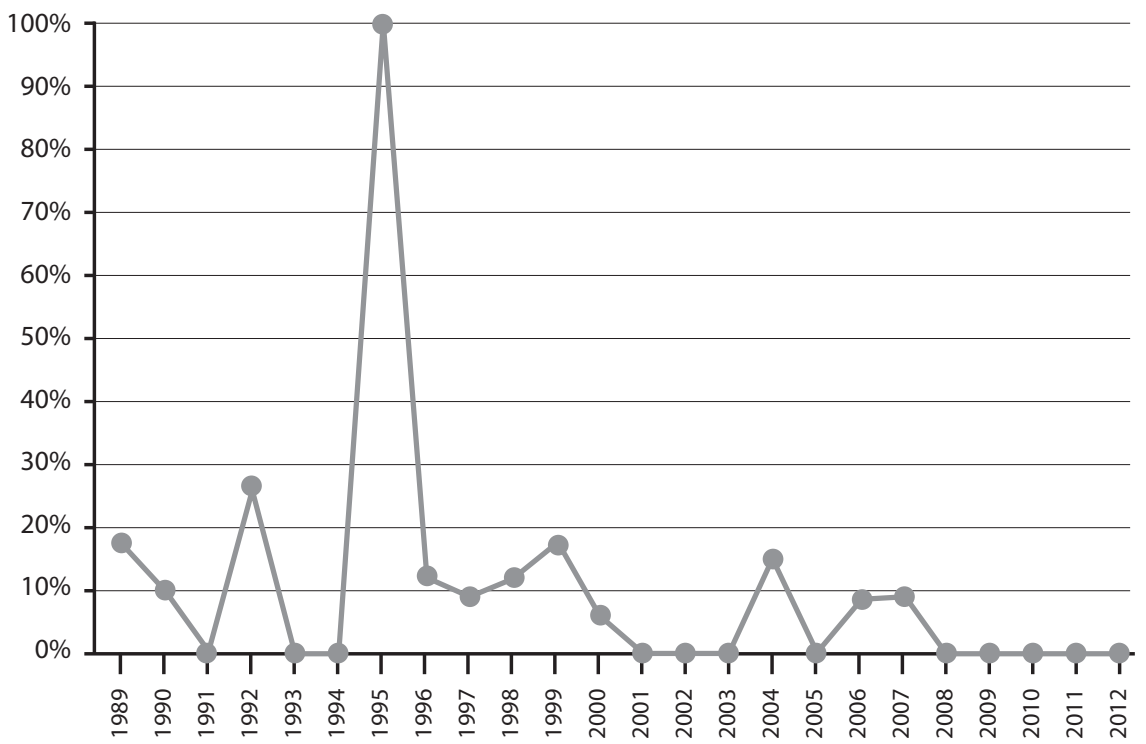


No que concerne à taxa de sucesso das ADIs, considerando-se a temática proposta e o resultado obtido, é visível que o número de ações procedentes e procedentes em parte ainda é maior nas questões que envolvem interesse corporativo. São 20 ações procedentes ou procedentes em parte no que atine ao interesse corporativo, enquanto apenas $14 \mathrm{ADIs}$ versam sobre interesse público.

\section{Gráfico 7 - RelaÇÃo entre os ANOS E A PREJUdicialidade do PEDIdO}

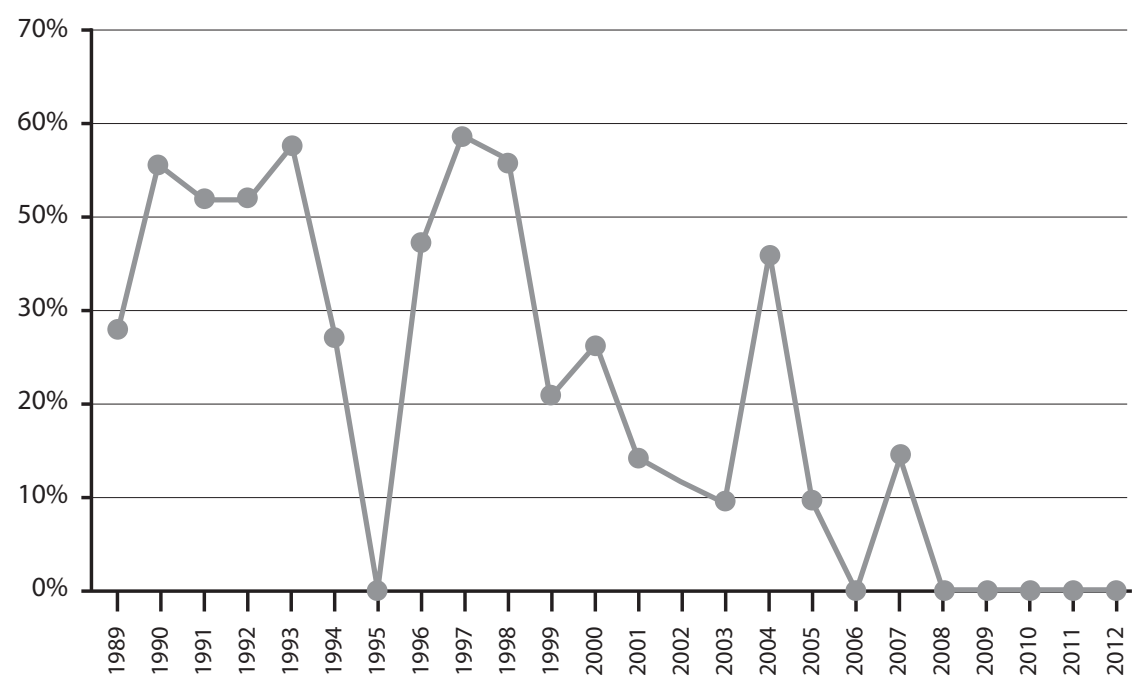

Quanto às ações consideradas prejudicadas, há um número relativamente grande de demandas neste sentido, totalizando 51 ações. A caracterização da prejudicialidade não significa propriamente o insucesso do ator, mas, em certo sentido, a relevância da discussão e até mesmo a razão da argumentação jurídica, visto que tal prejudicialidade advém da perda do objeto, por alterações ou exclusões da lei ou do ato normativo no ordenamento jurídico pátrio.

Neste sentido, no que se refere a esta variável, pode-se enquadrar que a ação do Conselho Federal da Ordem dos Advogados do Brasil gera, no mínimo, custos políticos para os Poderes Públicos, ao provocar a revisão dos atos praticados, bem como a modificação e até mesmo a exclusão das regras jurídicas do sistema. 
GrÁfico 8 - RELAÇÃo ENTRE OS ANOS E O NÃO CONHECIMENTO DO PEDIDO

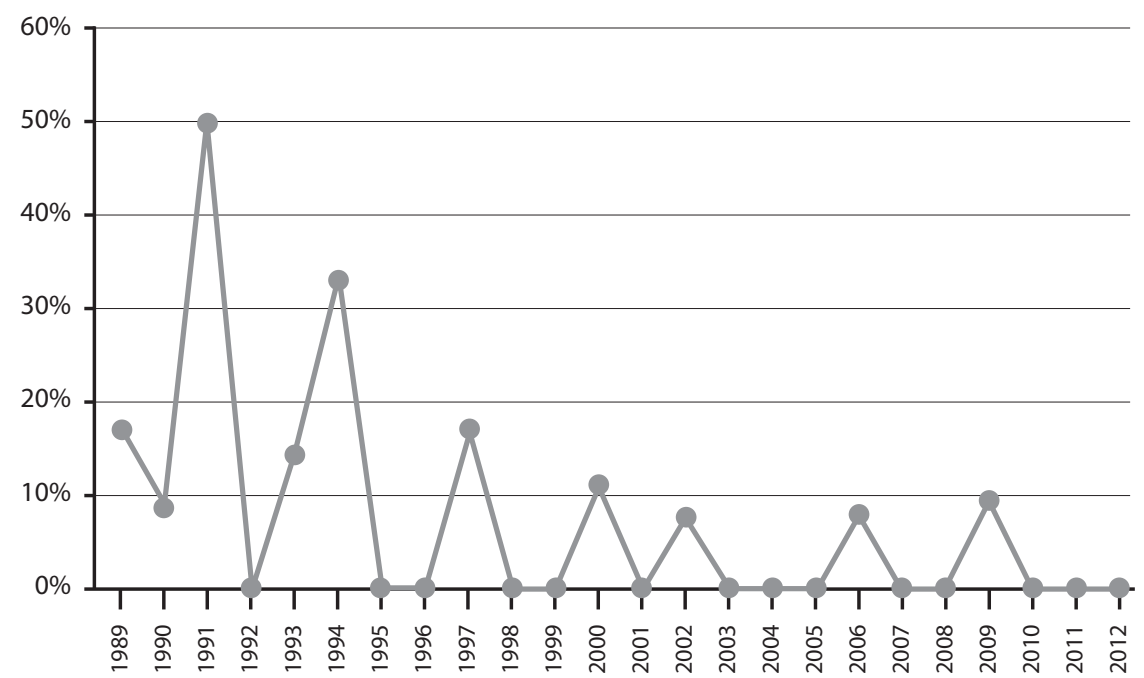

No Gráfico 8 percebem-se percentuais mínimos de ações não conhecidas ou que tiveram negado o seu seguimento. Ademais, apontam para uma maior adequação da entidade, com o passar dos anos, relativamente ao objeto das questões discutidas. Isto denota, em certo sentido, a relevância das discussões constitucionais adjudicadas pelo ator ao Poder Judiciário. 


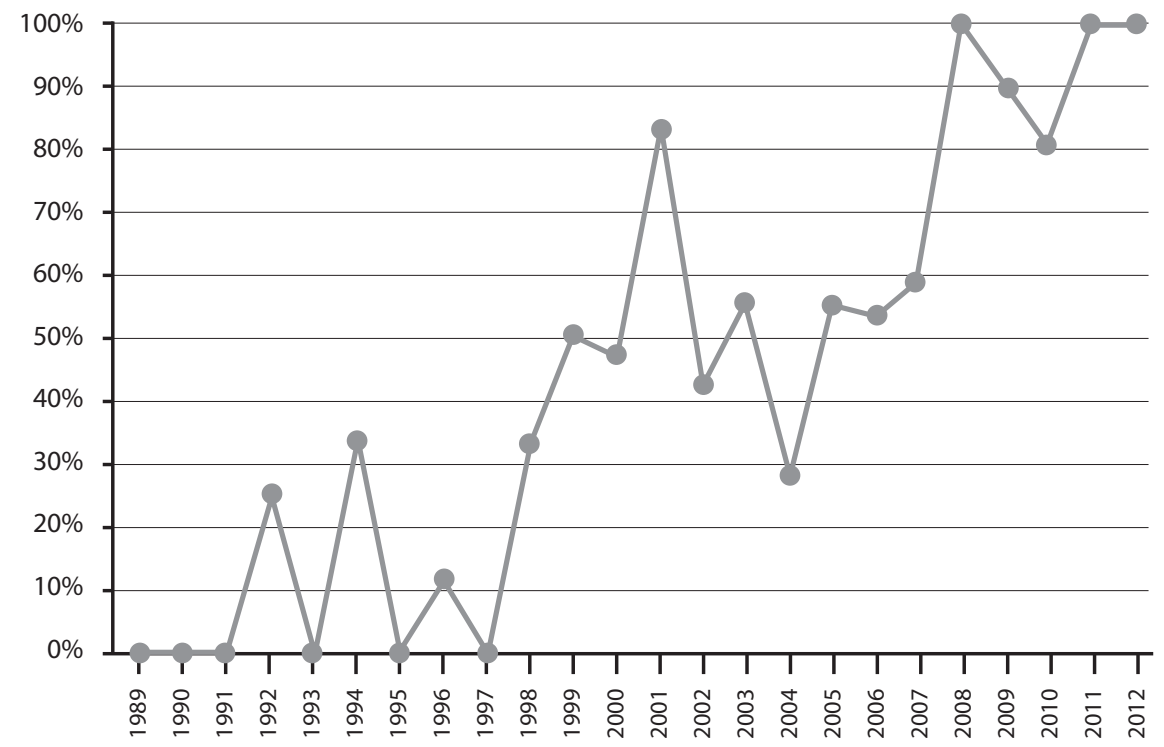

Por último, o Gráfico 9 denota um alto índice de ações diretas de inconstitucionalidade aguardando julgamento. Este é um dos pontos críticos da atividade jurisdicional, que revela em grande medida a morosidade do Judiciário. Como se percebe, há percentuais significativos de ADIs aguardando julgamento frente ao universo de ações do respectivo ano, principalmente a partir de 1998.

Em trabalho recente, Barbosa (2009) ressalta que não existem mecanismos de controle de agenda no STF no que concerne às ações diretas de inconstitucionalidade. A sistemática adotada pelo Regimento Interno do Supremo Tribunal Federal possibilita aos ministros uma escolha sobre aquilo que vai ou deve ser julgado. Foi percebido, também, que as questões políticas ou de clamor popular elevado costumam ser enfrentadas pela Corte Constitucional como prioritárias, ensejando uma apreciação mais célere destas matérias.

Portanto, visualiza-se uma mudança significativa na atuação da $\mathrm{OAB}$, voltando-se para questões que versam sobre interesse público. Esta mudança de paradigma coaduna-se com suas prerrogativas institucionais e com a própria construção jurisprudencial do Supremo Tribunal Federal.

Entretanto, esta reorientação não tem significado um aumento do sucesso das demandas propostas pela instituição. Percebe-se aqui um mecanismo de autocontenção, conforme construção de Posner (1983), recusando-se o Tribunal a julgar determinadas 
ações que versam sobre interesse público, diante dos possíveis custos políticos advindos desta atuação. Conforme salienta o autor:

Judicial self-restraint can have other sources besides personality. It can arise from a straightforward concern with the overload on the federal courts system-a natural concern for any federal judge to feel today-or from fear of retribution by the political branches against a hyperactive judiciary. It can also come from theory-from the "capital preservation" theory that I mentioned earlier, or from a theory of the separation of powers such as was implicit in my earlier rejection of the idea that a judge should decide cases as the agent of the political party that supported his appointment. And judicial self-restraint is often opportunistic-as, of course, judicial activism often is also. The judge does not like his brethren's policy preferences but rather than say so he takes the "neutral" stance that the courts ought to be doing less of everything. (POSNER, 1983, p. 19)

Não obstante a estes resultados, que apontam para um número expressivo de ADIs sobre interesse público aguardando julgamento, cabe-nos pontuar que os percentuais expressos no Gráfico 1 são extremamente significativos, visto que se tende a imaginar a utilização do instrumental das ADIs pela OAB visando substancialmente à proteção dos interesses corporativos da instituição.

Ocorre que, diferentemente de outros atores de âmbito essencialmente privado, como a AMB, ANMP, ANAMATRA e CNI, a ausência de pertinência temática faz com que o CFOAB se lance a propor no Supremo Tribunal Federal questões atinentes ao interesse público. Alguns estudos apontam, inclusive, para um baixo aproveitamento na atuação daqueles atores por meio da ADI (CARVALHO; SANTOS; GOMES NETO, 2012).

Ao analisar o histórico das ações propostas pelo CFOAB, observa-se que em um primeiro momento a sua utilização era voltada principalmente à discussão de aspectos relativos ao exercício da advocacia, como forma de consolidação da atuação profissional do advogado. Este momento, referente à década de 1990, condiz com a situação vivenciada pela OAB no cenário nacional. Segundo Motta (2006):

Vigilante e atuante em todos os episódios que poderiam ameaçar a delicada tarefa de consolidação democrática - a liderança que assumiu por ocasião do impeachment é o exemplo mais evidente desse compromisso -, a Ordem vai estar "liberada", a partir de então, para se dedicar às questões "internas", mais ligadas à sua face corporativa de representação dos advogados. A construção da sede em Brasília - a primeira, em 1990, e a segunda, dez anos depois -, e a elaboração de um novo Estatuto, em 1994, marcaram, sem dúvida, o investimento em um projeto que visou a adequar a Ordem, ao mesmo 
tempo, à nova realidade política do país e às novas condições do mercado profissional dos advogados brasileiros. (MOTTA, 2006, p. 7-8)

Mesmo neste contexto de reorganização institucional, houve momentos de atuação pública, principalmente na adoção pelo Estado Brasileiro do Programa Nacional de Privatização (PND), criado no governo Collor e desenvolvido no governo Fernando Henrique, assim como no surgimento do instituto da Medida Provisória (MP), fundamentada na celeridade da atuação legislativa, mas que, na verdade, segundo entendimento da própria OAB, consubstanciava-se como uma usurpação legislativa por parte do Poder Executivo. A par deste contexto histórico, Motta (2006) informa que:

O fortalecimento das instituições democráticas do país, depois do difícil teste de resistência a que haviam sido submetidas, abriu caminho para uma série de medidas oriundas do Executivo com o objetivo de dar um novo formato ao tradicional aparato estatal brasileiro. Iniciadas no governo de Itamar Franco (1993-94), e aceleradas ao longo dos dois mandatos de Fernando Henrique Cardoso (1995-2002), as chamadas "reformas" foram combatidas pela OAB, especialmente as que visavam a privatizar algumas atividades e serviços antes controlados/monopolizados pelo Estado. Por outro lado, o uso das medidas provisórias como forma de "agilizar" o processo legislativo mereceu mais do que críticas severas, e levou a Ordem, principalmente pelo emprego de Ações Diretas de Inconstitucionalidade, a constantes choques com o Executivo.

(MOTTA, 2006, p. 7)

Posteriormente, nota-se uma atuação voltada essencialmente ao interesse público, participando a entidade da discussão sobre a constitucionalidade de assuntos de grande relevância nacional. Pode-se considerar que, com o passar dos anos, o paulatino fortalecimento da democracia fez com que a $\mathrm{OAB}$ voltasse sua atuação visando à legitimação das suas prerrogativas constitucionais e institucionais, passando a tratar sobre assuntos afetos à seara pública. Não é possível se sustentar uma ampla participação nas principais instituições políticas nacionais sem um efetivo respaldo político, caracterizado, no contexto do ator ora analisado, por uma atuação efetivamente pública.

É neste cenário que o próprio STF publica o acórdão da ADI 3.026/DF, frente a questionamentos sobre a natureza jurídica da OAB, feitos pela Procuradoria-Geral da República. Nesta decisão, o Supremo reafirma o seu entendimento sobre a importância ímpar da instituição na democracia brasileira.

A atuação voltada ao interesse público é tão notória que, reforçando o argumento da atuação pública, foram propostas pelo CFOAB, nos últimos dois anos, 44 ações diretas de inconstitucionalidade versando sobre interesse público e apenas 1 versando sobre interesse corporativo. 
No que se refere a este período, verifica-se sua atuação sobre questões de grande repercussão nacional, as quais podemos distribuir em seis grandes blocos:

(1) Pensão vitalícia a ex-governadores;

(2) Pensão a viúvas e filhos de ex-governadores;

(3) Eleições e partidos políticos;

(4) Precatórios;

(5) Incidência de ICMS;

(6) Competência para julgamento do governador de Estado.

Dentre este universo de ações propostas, destacamos as ações do primeiro e do último bloco; a primeira é relativa à previsão legislativa de pensão para ex-governadores e a última discorre sobre a competência para julgamento do governador de Estado.

Sobre a questão das pensões para ex-governadores, houve uma larga campanha capitaneada pela OAB. Durante este processo, sua exposição midiática como defensora da sociedade contra os abusos estatais foi intensa. Neste período, foram impetradas 9 ADIs, ${ }^{21}$ fundamentadas no entendimento de que a atual Constituição Federal não prevê nem autoriza a instituição de qualquer subsídio para quem não é ocupante de qualquer cargo público (eletivo ou efetivo), bem como caracterizando que há uma flagrante violação aos princípios da moralidade e da impessoalidade, presentes no artigo 37 da Constituição Federal. É importante pontuar, inclusive, que as repercussões da mídia fazem parte da instrução de várias ações, por meio da juntada de matérias produzidas por veículos de grande tiragem nacional.

Quanto às legislações estaduais que preveem a competência das Assembleias Legislativas para julgamento dos governadores de Estado, a OAB promove uma verdadeira batalha contra as Assembleias Estaduais. ${ }^{22}$ São 20 ações diretas de inconstitucionalidade, frente a leis estaduais legisladas por 20 Assembleias Legislativas Estaduais.

Nestes casos, o CFOAB alega a inconstitucionalidade da previsão contida nas Constituições Estaduais que estabelecem a competência das Assembleias Legislativas para processar e julgar os governadores dos seus Estados, visto que se trata de matéria processual penal, a qual cabe privativamente à União legislar. Alega a entidade que tal previsão agride substancialmente o princípio republicano, o princípio da separação dos poderes e o relativo ao acesso à jurisdição, previstos respectivamente nos artigos $1^{\circ}, 2^{\circ}$ e $5^{\circ}$ da CF, e que são essenciais a um Estado Democrático de Direito.

Trata-se de uma discussão eminentemente pública, relacionada à organização do Estado brasileiro, versando sobre o papel do Poder Legislativo federal e estadual. Diz respeito a uma dimensão pública, mas, ao mesmo tempo, a uma dimensão essencialmente política e que mexe com as macroestruturas do Estado. Este ponto também é extremamente significativo, pois a discussão levantada em sede constitucional desnuda relações clientelísticas entre o Executivo e o Legislativo no âmbito subnacional. 
Um dos pontos importantes a ser ressaltado na análise das ADIs é que, em todas as ações, o Conselho Federal da OAB fundamenta a propositura em sua legitimação universal, considerando-se "defensor da cidadania e da Constituição". Ou seja, mesmo naquelas ADIs que versam sobre interesses essencialmente corporativos, o CFOAB legitima sua atuação com uma roupagem pública. Paralelamente, ainda houve no período uma massificação midiática da $\mathrm{OAB}$, o que acabou por reforçar seu papel de porta-voz dos interesses da sociedade.

No que atine à sua atuação na seara da adjudicação constitucional, o CFOAB antecipa informações à população sobre a propositura das ações diretas de inconstitucionalidade. Ademais, salienta conquistas jurídicas frente ao Supremo Tribunal Federal, na disputa de questões que envolvem os atos dos Poderes Públicos constituídos. Portanto, entendemos que todo este instrumental configura-se como um importante mecanismo de legitimação da atuação da OAB no controle concentrado de constitucionalidade.

\section{CONSIDERAÇÕES FINAIS}

O presente artigo buscou trazer a discussão sobre a atuação da Ordem dos Advogados do Brasil no controle judicial concentrado, tendo-se como parâmetro as ações diretas de inconstitucionalidade, consideradas o mais importante mecanismo na arena da adjudicação constitucional (CARVALHO, 2009; MENDES, 2011).

Inicialmente, foram lançadas as bases de atuação do Conselho Federal da OAB no STF, insculpidas na ausência de pertinência temática, ausência de controle estatal direto e caracterização da entidade como serviço público independente, formatada na própria jurisprudência do Tribunal Constitucional, cujo marco é, sem dúvida, a ADI 3.026/DF.

Um dos pontos relevantes para a discussão é que as prerrogativas do CFOAB são sui generis, atípicas, não sendo observadas em nenhum outro país sul-americano. A forma como a própria $\mathrm{OAB}$ e os integrantes do Poder Judiciário reconhecem-na na sistemática jurídica do país traz subsídios importantes para caracterização do nível de importância política atingido no cenário nacional.

Mesmo sendo um forte ator, em essência de âmbito privado, sua participação no processo de redemocratização produziu um significativo rol de prerrogativas, típicas de um ator eminentemente público, e que sinalizam para um caráter de essencialidade, o qual não é percebido nos países da América do Sul que vivenciaram um processo político similar. Desta forma, o Brasil produziu um desenho institucional onde a defesa das garantias constitucionais foi dividida com um ator que não é controlado pelos poderes constituídos, ou seja, que não possui qualquer tipo de accountability, seja vertical ou horizontal.

A partir do levantamento inicial dos temas propostos em sede de ação direta de inconstitucionalidade, percebe-se que há uma significativa atuação visando o interesse 
público, o que vai, aparentemente, de encontro a construções teóricas que informam que os grupos provocam o Judiciário visando ampliar e fortalecer seus próprios interesses (NEUBAUER et al, 2010).

Mas o ponto crucial desta discussão é a pertinência temática, a qual viabiliza uma diferenciação clara da $\mathrm{OAB}$ com outros atores de âmbito essencialmente privado, como a CNI e a AMB (BARROSO, 2012). Enquanto a atuação das confederações sindicais e entidades de classe de âmbito nacional, previstas no inciso IX do artigo 103 da CF, volta-se aos interesses privados, o Conselho Federal da OAB, legitimado em outro inciso (inciso VII), vale-se de todo o seu arsenal político, discutindo questões que vão desde o interesse corporativo até questões que versam puramente sobre interesse público.

Contudo, destaque-se que o objetivo principal da entidade é, afinal, o seu próprio fortalecimento. Parece-nos que a Ordem dos Advogados do Brasil elege determinadas matérias em contextos políticos favoráveis, de ampla discussão nacional, de forma a consolidar frente à população a sua imagem de protetora dos direitos e garantias individuais e coletivos. Foi dada uma feição pública e, em determinados contextos políticos, a OAB sente a necessidade de legitimá-la. E, atuando nesta direção, acaba por legitimar diretamente todo o arsenal político auferido pela Constituição Federal.

No caso brasileiro aqui estudado, o fato de o CFOAB não possuir amarras institucionais com os Poderes Públicos constituídos possibilita em vários momentos uma atuação independente, ao levar demandas ao Supremo Tribunal Federal, funcionando como um efetivo mecanismo de controle da atividade normativa do Estado. A própria entidade entende que estas prerrogativas institucionais são indispensáveis à proteção da democracia brasileira. Contudo, a ausência de qualquer espécie de accountability (institucional, social etc.) pode degenerar tal arranjo, pois, estaríamos sempre pressupondo que o CFOAB é composto de pessoas de aspirações democráticas e republicanas.

Como demonstrado no presente trabalho, os dados apontam para uma maior taxa de sucesso das ações que versam sobre interesse corporativo, dentre o universo de ADIs julgadas, aliada a uma significativa demora na apreciação das questões que envolvem interesse público. Em termos de revisão judicial abstrata, este ponto pode denotar duas situações distintas: por um lado, os custos maiores para o Poder Judiciário apreciar matérias que versam sobre interesse efetivamente público (POSNER, 1983); por outro, que o STF, em termos concretos, vem julgando apenas ações que trazem em seu bojo o fortalecimento de interesses corporativos da OAB.

Contudo, é fundamental relembrar que há um número de ADIs versando sobre interesse público que também tiveram sucesso e outras, propostas principalmente nos últimos três anos, ainda aguardando julgamento.

Outro ponto a ser ressaltado é que, mesmo diante da menor taxa de sucesso obtida no julgamento das ADIs de interesse público, consideramos que o principal motivo para a entidade continuar propondo demandas neste sentido é a manutenção de sua agenda política, firmando uma posição ativa de proteção dos interesses da coletividade. 
Ademais, esta atuação reveste-se como uma instrumentalização do seu poder, reforçando a $\mathrm{OAB}$ o seu caráter essencial ao tratar sobre as principais questões de cunho político-democrático no âmbito do Supremo Tribunal Federal. O fato é que, historicamente, a OAB, enquanto associação de advogados, sempre teve voz ativa nas principais questões do país. Contemporaneamente, amparada por uma legitimação constitucional, a entidade passou a possuir um verdadeiro arsenal jurídico-político, estando presente nas principais discussões sobre a vida pública do país.

Finalmente, a partir deste trabalho, vislumbramos que se torna muito importante salientar a necessidade de estudos comparados sobre a atuação das corporações de advogados e em que medida tal atuação é significativa em termos de fortalecimento e qualidade da democracia, especialmente no contexto latino-americano.

: ARTIGO APROVADO (12/02/2014) : RECEBIDO EM 20/11/2012

\section{NOTAS}

1 Controle Concentrado - o Tribunal constitucional provocado por uma ação direta de (in)constitucionalidade decidirá sobre a lei em tese. Portanto, não é necessário a existência de um conflito jurídico concreto. A norma in abstractu é atingida e seu efeito é erga omnes (contra todos). Nesse tipo de controle, o Tribunal possui o monopólio sobre o controle de constitucionalidade.

2 Controle Difuso - qualquer juiz pode (tem competência para) declarar a inconstitucionalidade das leis e atos normativos no julgamento de casos concretos. Nesse tipo de controle não se atinge a lei em tese, ou seja, os julgados só afetam o objeto jurídico em questão e as partes envolvidas.

3 Para efeitos de um maior aprofundamento dos aspectos políticos do instituto da revisão judicial vide Carvalho (2010).

4 Disponível em: <http://www.stf.jus.br/portal/principal/principal.asp>. Acesso em: 9 fev. 2014.

5 O artigo 133 da Constituição Federal é um dos resultados mais marcantes da presença maciça da OAB na Assembleia Nacional Constituinte de 1987, tendo a seguinte previsão: "Art. 133. O advogado é indispensável à administração da justiça, sendo inviolável por seus atos e manifestações no exercício da profissão, nos limites da lei”.

6 “Art. 44. A Ordem dos Advogados do Brasil (OAB), serviço público, dotada de personalidade jurídica e forma federativa, tem por finalidade:

I - defender a Constituição, a ordem jurídica do Estado democrático de direito, os direitos humanos, a justiça social, e pugnar pela boa aplicação das leis, pela rápida administração da justiça e pelo aperfeiçoamento da cultura e das instituições jurídicas;

II - promover, com exclusividade, a representação, a defesa, a seleção e a disciplina dos advogados em toda a República Federativa do Brasil”. 
7 Destacamos, a seguir, os aspectos que reputamos mais relevantes da ADI 3.026/DF: "AÇÃO DIRETA DE INCONSTITUCIONALIDADE. $\S 1^{\circ}$ DO ARTIGO 79 DA LEI N. 8.906, $2^{\text {a }}$ PARTE. 'SERVIDORES' DA ORDEM DOS ADVOGADOS DO BRASIL. PRECEITO QUE POSSIBILITA A OPÇÃO PELO REGIME CELETISTA. COMPENSAÇÃO PELA ESCOLHA DO REGIME JURÍDICO NO MOMENTO DA APOSENTADORIA. INDENIZAÇÃO. IMPOSIÇÃO DOS DITAMES INERENTES À ADMINISTRAÇÃO PÚBLICA DIRETA E INDIRETA. CONCURSO PÚBLICO (ART. 37, II DA CONSTITUIÇÃO DO BRASIL). INEXIGÊNCIA DE CONCURSO PÚBLICO PARA A ADMISSÃO DOS CONTRATADOS PELA OAB. AUTARQUIAS ESPECIAIS E AGÊNCIAS. CARÁTER JURÍDICO DA OAB. ENTIDADE PRESTADORA DE SERVIÇO PÚBLICO INDEPENDENTE. CATEGORIA ÍMPAR NO ELENCO DAS PERSONALIDADES JURÍDICAS EXISTENTES NO DIREITO BRASILEIRO. AUTONOMIA E INDEPENDÊNCIA DA ENTIDADE. PRINCÍPIO DA MORALIDADE. VIOLAÇÃO DO ARTIGO 37, 'CAPUT', DA CONSTITUIÇÃO DO BRASIL. NÃO OCORRÊNCIA. 1. A Lei n. 8.906, artigo 79, § 1º, possibilitou aos "servidores" da $\mathrm{OAB}$, cujo regime outrora era estatutário, a opção pelo regime celetista. Compensação pela escolha: indenização a ser paga à época da aposentadoria. 2. Não procede a alegação de que a OAB sujeita-se aos ditames impostos à Administração Pública Direta e Indireta. 3. A OAB não é uma entidade da Administração Indireta da União. A Ordem é um serviço público independente, categoria ímpar no elenco das personalidades jurídicas existentes no direito brasileiro. 4. A OAB não está incluída na categoria na qual se inserem essas que se tem referido como 'autarquias especiais' para pretender-se afirmar equivocada independência das hoje chamadas 'agências'. 5. Por não consubstanciar uma entidade da Administração Indireta, a $O A B$ não está sujeita a controle da Administração, nem a qualquer das suas partes está vinculada. Essa não-vinculação é formal e materialmente necessária. 6. A OAB ocupa-se de atividades atinentes aos advogados, que exercem função constitucionalmente privilegiada, na medida em que são indispensáveis à administração da Justiça [artigo 133 da CB/88]. É entidade cuja finalidade é afeita a atribuições, interesses e seleção de advogados. Não há ordem de relação ou dependência entre a OAB e qualquer órgão público. 7. A Ordem dos Advogados do Brasil, cujas características são autonomia e independência, não pode ser tida como congênere dos demais órgãos de fiscalização profissional. A OAB não está voltada exclusivamente a finalidades corporativas. Possui finalidade institucional. 8. Embora decorra de determinação legal, o regime estatutário imposto aos empregados da $\mathrm{OAB}$ não é compatível com a entidade, que é autônoma e independente. 9. Improcede o pedido do requerente no sentido de que se dê interpretação conforme o artigo 37, inciso II, da Constituição do Brasil ao "caput" do artigo 79 da Lei n. 8.906, que determina a aplicação do regime trabalhista aos servidores da OAB. 10. Incabível a exigência de concurso público para admissão dos contratados sob o regime trabalhista pela OAB. 11. Princípio da moralidade. Ética da legalidade e moralidade. Confinamento do princípio da moralidade ao âmbito da ética da legalidade, que não pode ser ultrapassada, sob pena de dissolução do próprio sistema. Desvio de poder ou de finalidade. 12. Julgo improcedente o pedido.

ACÓRDÃO: Vistos, relatados e discutidos estes autos, acordam os Ministros do STF, em sessão plenária, sob a presidência da Min. Ellen Gracie, na conformidade da ata do julgamento e das notas taquigráficas, por maioria de votos, julgar improcedente o pedido.

Brasília, 8/06/2006. EROS GRAU - Relator”. (DJ 29/09/2006, Ementário 2249-3, Tribunal Pleno)

8 No caso da arguição abstrata de inconstitucionalidade, a literatura jurídica pátria aponta que a pertinência temática foi uma estratégia jurisprudencial criada pelo Supremo Tribunal Federal para controlar o aumento significativo de demandas após a ampliação do rol de legitimados efetivada pela Emenda Constitucional n. 3/93, significando tal pertinência a congruência temática entre as finalidades estatutárias ou os interesses da unidade federativa, e o conteúdo da norma impugnada. Neste sentido, houve a divisão entre os legitimados ativos universais, que não possuem impedimento para propositura quanto ao objeto, como é o caso do Conselho Federal da Ordem dos Advogados do Brasil, e os legitimados ativos especiais, os quais necessitam comprovar o vínculo objetivo de pertinência entre a norma impugnada e as finalidades institucionais ou os interesses da unidade federativa (CLÈVE, 1995; LOURENÇO, 1998; BARROSO, 2004; MARTINS et al., 2005; MENDES, 2011; DANTAS, 2012).

9 STF, RTJ, 142:383, 1992 ADIn 3/DF, rel. Min. Moreira Alves: "Em se tratando do Conselho Federal da Ordem dos Advogados do Brasil, sua colocação no elenco que se encontra no mencionado artigo, e que a distingue das demais entidades de classe de âmbito nacional, deve ser interpretada como feita para lhe permitir, na defesa da ordem jurídica com o primado da Constituição Federal, a propositura de ação direta de inconstitucionalidade contra qualquer ato normativo que possa ser objeto dessa ação; independe do requisito da pertinência temática entre o seu conteúdo e o interesse dos advogados como tais de que a Ordem é entidade de classe" (grifos dos autores).

10 Recortamos a seguir o trecho da ementa da ADI 3.026, que trata sobre a ausência de controle externo da OAB: 3.026-“5. Por não consubstanciar uma entidade da Administração Indireta, a OAB não está sujeita a controle da Administração, nem a qualquer das suas partes está vinculada. Essa não-vinculação é formal e materialmente necessária”. 
11 Para efeitos de um maior aprofundamento sobre as bases de atuação jurídico-política do Conselho Federal da Ordem dos Advogados do Brasil, vide "Os donos do poder: a OAB e seu papel na revisão judicial concentrada" (BARBOSA, 2012).

12 Vide inteiro teor da ADI 3.026/DF.

13 Para a construção da tabela em questão, desconsideramos as alusões referentes a "advogado(s)" presentes em português na nomenclatura Advogado-Geral da União (Constituição do Brasil), visto que se trata de um cargo público, diferente do nosso objeto de análise.

14 Ao analisar as elites jurídicas no Brasil, Almeida (2010) pontua que os grupos profissionais mais radicais na agenda de transformação da justiça são visivelmente ausentes das estruturas do campo político da justiça e dos círculos das elites da administração da justiça estatal. Inclusive, ao tratar especificamente sobre a OAB, o autor salienta que, não obstante a massificação da advocacia, a entidade tem conseguido conter esta expansão através de uma política de controle sobre o ensino jurídico e de separação de um estrato de elite da profissão, por meio do que chama de "grande advocacia", consubstanciada na organização de escritórios e prestação de serviços, que acaba por se corporificar como um verdadeiro modelo para todos os estratos profissionais, permitindo a aproximação deste segmento da advocacia com o polo dominante do campo jurídico e do campo político das instituições judiciais.

15 Dados retirados da página eletrônica do Supremo Tribunal Federal (disponível em: <http://www.stf.jus.br/ portal/principal/principal.asp>. Acesso em: 9 fev. 2014) apontam, até o mês de julho de 2012, para a propositura de 4.814 ADI, frente a $261 \mathrm{ADPF}, 31 \mathrm{ADC}$ e $19 \mathrm{ADO}$.

16 Existem diversos trabalhos que fazem alusão à dinâmica geral do processo de judicialização da política via revisão abstrata da legislação no Brasil; no presente artigo interessa-nos, exclusivamente, a performance da OAB neste cenário.

17 Para a caracterização da taxa de sucesso dos atores elencados, consideram-se aqui as ADI apreciadas pelo STF, com decisão liminar ou de mérito, ou seja, aquelas ações cuja decisão se enquadra entre as variáveis procedente, procedente em parte ou improcedente.

18 O banco de dados em questão foi produzido pelo Departamento de Ciência Política da Universidade Federal de Pernambuco - PPGCP/UFPE, podendo ser encontrado em Barbosa (2012).

19 Neste contexto, exemplificativamente, várias ações que tinham por objeto a discussão do valor base para custas processuais (taxas judiciárias) foram consideradas como de interesse corporativo, visto que afetam diretamente a atividade profissional do advogado.

20 Vide Gráfico 1 e Tabela 4.

21 São propostas, neste sentido, as ADIs 4.544, 4.545, 4.547, 4.552, 4.553, 4.555, 4.556, 4.562 e 4.575.

22 Foram propostas para tal fim as seguintes ações diretas de inconstitucionalidade: ADIs 4.764, 4.765, 4.766, $4.771,4.772,4.773,4.777,4.778,4.781,4.790,4.791,4.792,4.793,4.797,4.798,4.799,4.800,4.804,4805,4.806$ e 4.811 .

\section{REFERÊNCIAS BIBLIOGRÁFICAS}

AGRA, Walber de Moura. A fiscalização abstrata de constitucionalidade. In: AGRA, Walber de Moura; ALMEIDA FILHO, Agassiz (Org.). Comentários à reforma do Poder Judiciário. Rio de Janeiro: Forense, 2005.

ALMEIDA, Frederico Normanha Ribeiro de. A Nobreza Togada: As elites jurídicas e política da justiça no Brasil. Tese de Doutorado defendida no DCP-USP. São Paulo: USP, 2010. 
ALMOND, Gabriel; POWELL, Bingham. Comparative Politics: a development approach. Boston: Little, Brown, 1966. BARBOSA, Luis Felipe Andrade. Revisão Judicial e Controle de Agenda no Supremo Tribunal Federal: Estudo quantitativo e qualitativo sobre as Adins julgadas pelo Tribunal Constitucional. Recife: UFPE, 2009.

Os donos do poder: a $O A B$ e o seu papel na revisão judicial concentrada.

Dissertação de Mestrado defendida no PPGCP-UFPE. Recife: UFPE, 2012.

BARBOSA, Leon Victor Queiroz; GOMES NETO, José Mário Wanderley; FIGUEIREDO FILHO, Dalson Brito. Brazilian Supreme Court and the rule of law construction: building the Legislative Quality Index (LQI). Stanford: ISNIE, 2011.

BARROSO, Luís Roberto. O controle de constitucionalidade no direito brasileiro: exposição sistemática da doutrina e análise crítica da jurisprudência. São Paulo: Saraiva, 2004.

CARVALHO, Ernani. Os dilemas do controle de constitucionalidade no ordenamento jurídico brasileiro. Política Hoje, v. 1, n. 10, Recife, p. 153-168, 1999.

. Judicialização da política no Brasil: controle de constitucionalidade e racionalidade política. Análise Social, v. XLIV, n. 191, abr., Lisboa, p. 315-335, 2009.

. Trajetória da revisão judicial no desenho constitucional brasileiro: tutela, autonomia e judicialização. Sociologias, n. 23, jan./abr, Porto Alegre, p. 176-207, 2010.

CARVALHO, Ernani; SANTOS, Manoel; GOMES NETO, José Mário Wanderley. Interactions between the Brazilian Supreme Court and the National Industry Union in Corporative Political Disputes. Madrid: IPSA, 2012.

CLÈVE, Clémerson Merlin. A fiscalização abstrata de constitucionalidade no direito brasileiro. São Paulo: Editora Revista dos Tribunais, 1995.

DAHL, Robert. Decision-making in a democracy: the supreme court as a national policy-maker. Journal of Public Law, v. 6, n. 1, Yale, 1957.

DANTAS, Ivo. Constituição \& processo. 2. ed. Curitiba: Juruá, 2012.

DINIZ, Eli e BOSCHI, Renato. O Legislativo como arena de interesses organizados: a atuação dos lobbies empresariais. Locus Revista Histórica, v. 5, n. 1, Rio de Janeiro, p. 7-32, 1999.

GINSBURG, Tom. Judicial review in new democracies: constitutional courts in Asian cases. Nova Iorque: Cambridge University Press, 2003.

HIRSCHL, Ran. The judicialization of mega-politics and the rise of political courts, Annual Review of Political Science, Palo Alto, 2008.

. Towards juristocracy - the origins and consequences of the New Constitutionalism. Cambridge, Massachusetts e Londres: Harvard University Press, 2004.

LOURENÇO, Rodrigo Lopes. Controle da constitucionalidade à luz da jurisprudência do STF. Rio de Janeiro: Forense, 1998.

MARTINS, Ives Gandra da Silva; MENDES, Gilmar Ferreira. Controle concentrado de constitucionalidade: comentários à Lei n. 9.868, de 10-11-1999. 2. ed. São Paulo: Saraiva, 2005.

MELLO, Celso Antônio Bandeira de. Curso de direito administrativo. 20. ed. São Paulo: Malheiros, 2006.

MENDES, Gilmar Ferreira; BRANCO, Paulo Gustavo Gonet. Curso de direito constitucional. 6. ed. São Paulo, Saraiva, 2011.

MOTTA, Marly Silva da. A ordem dos advogados do Brasil: entre a corporação e a instituição. Ciência Hoje, v. 39, p. 32-37, dez. Rio de Janeiro, 2006.

NEUBAUER, David W.; MEINHOLD, Stephen S. Judicial process: law, courts, and politics in the United States. Boston: Wadsworth Cengage Learning, 2010.

POSNER, Richard A. The meaning of judicial self-restraint. The Indiana Law Journal, v. 59, n. 1, 1983.

SALISBURY, Robert. Interest groups. In: POLSBY, N. \& GREENSTEIN, F. (orgs.) Handbook of Political Science, v. 4. Boston: Addison-Wesley 190 Publishing Company, 1975.

SANTOS, Manoel. O parlamento sob influência: o lobby da indústria na Câmara dos Deputados. Recife: UFPE, 2011. SWEET, Alec Stone. Governing with judges: constitutional politics in Europe. Oxford: University Press, 2000.

TATE, C. Neal e VALLINDER, Torbjorn. The global explosion of judicial power. Nova Iorque e Londres: New York University Press, 1995.

TAYLOR, Matthew M. Judging policy: courts and policy reform in democratic Brazil. Califórnia: Stanford University Press, 2008.

\section{Documentos oficiais}

BRASIL. Lei n. 8.906, de 4 de julho de 1994.

Political Database of The Americas. Disponível em: <http://pdba.georgetown.edu/>. Acesso em: 20 out. 2012. 
Portal da Câmara dos Deputados. Disponível em: <http://www.camara.gov.br/>. Acesso em: 20 out. 2012. Senado Federal. Disponível em: <http://www.senado.gov.br/sf/>. Acesso em: 20 out. 2012.

Supremo Tribunal Federal. Disponível em: <http://www.stf.jus.br/portal/principal/principal.asp > . Acesso em: 20 out. 2012.

\section{Ernani Carvalho}

Universidade Federal de Pernambuco Centro de Filosofia e Ciências Humanas Rua Acadêmico Hélio Ramos, s/n, $14^{\circ}$ andar Cidade Universitária - 50.670-901

$$
\text { Recife - PE - Brasil }
$$

ernani.carvalholapq.cnpq.br

Universidade Federal de Pernambuco Centro de Filosofia e Ciências Humanas Rua Acadêmico Hélio Ramos, s/n, $14^{\circ}$ andar Cidade Universitária - 50.670-901

$$
\text { Recife - PE - Brasil }
$$

lfelipeandrade.advagmail.com

Universidade Católica de Pernambuco Centro de Ciências Sociais Rua do Príncipe, 526 Boa Vista - 50050-900 Recife - PE - Brasil jmariowaunicap.br
DOUTOR EM CIÊNCIA POLítICA PELA USP Professor do Departamento de CiênCIA Política da UFPE VISITING RESEARCH DO DEPARTAMENTO DE CIÊNCIA POLÍtica da Universitat POMPEU Fabra

Luis Felipe Andrade Barbosa

Advogado

BACHAREL EM CIÊNCIAS SOCIAIS Mestre e Doutorando em Ciência Política Pela UfPE

\section{José Mário Wanderley Gomes Neto}

Doutorando em CiênCIA Política PELA UFPE Professor de Direito Processual da UNICAP 